\title{
Análisis general de las técnicas de intervención del Estado en la economía
}

\section{Carlos Saura Fructuoso ${ }^{1}$}

\section{RESUMEN}

El siguiente estudio tiene como fin un análisis general de las diferentes técnicas que dispone el Estado y el Sector Público para intervenir en la economía, tanto desde una vertiente restrictiva como aperturista de la iniciativa privada. A menudo, mecanismos como la nacionalización, liberalización, privatización y desregulación tienden a confundirse entre ellos, por lo que una adecuada delimitación resulta fundamental para proceder a un análisis jurídico de los diferentes efectos que se derivan de su utilización.

Palabras clave: intervención pública, economía, Estado, nacionalización, liberalización, privatización, desregulación, empresa pública, servicio público.

1 Profesor de Derecho Administrativo de la Universidad Complutense de Madrid (UCM), Madrid, España. Entre sus objetos de estudio destaca el Derecho Público y Administrativo Económico, el Derecho de la Competencia y el Derecho Europeo, así como el Derecho Aeronáutico. Ha sido investigador en las universidades de Harvard, Estados Unidos, y SciencePo de París, Francia. Es diplomado de la London School of Economics, Londres, Reino Unido, y del Insituto de Empresa, Madrid, España. Correo-e: c.saura@der.ucm. es Fecha de recepción: 19 de julio de 2015. Fecha de modificación: 24 de septiembre de 2015. Fecha de aceptación: 10 de octubre de 2015. Para citar el artículo: SAURA, C. (2015). Análisis general de las técnicas de intervención del Estado en la economía. Revista Digital de Derecho Administrativo n. ${ }^{\circ}$ 14, Universidad Externado de Colombia, pp. 27-43. DOI: http:// dx.doi.org/10.18601/21452946.n14.04 


\section{General analysis of State intervention techniques in the Economy}

\section{ABSTRACT}

The following study aims to give a general analysis of the different techniques the State and Public Sector use when intervening in the economy, from both a closed and open analysis of the economy. Frequently, methods such as nationalization, liberalization, privatization and deregulation tend to intersect and overlap, thus making it necessary to demarcate such concepts prior to a legal analysis of their different effects.

Keywords: Public intervention, Economy, State, nationalization, liberalization, privatization, deregulation, public company, public service.

\section{INTRODUCCIÓN}

El estudio que nos disponemos a realizar, por su propia extensión y finalidad, no pretende ser un análisis exhaustivo de cada una de las técnica a través de las cuales el Poder Público puede incidir en la esfera económica, sino que aspira a ser una introducción clara y concisa acerca de las diferentes posibilidades de que dispone el Estado para desarrollar sus políticas concretas, teleológicamente englobadas bajo la premisa fundamental del interés general.

Sobre cada una de estas técnicas que someramente tratamos existen multitud de monografías y artículos, tanto a nivel nacional como internacional, que abordan sus consecuencias desde diversas ópticas: jurídica, económica, política, sociológica, etc.

No obstante, generalmente se observa en la doctrina una tendencia a la confusión acerca del sentido y operatividad de cada técnica, mezclándose características de unas y otras. Si a ello le sumamos los tintes ideológicos que muchos autores se empecinan en otorgar, se produce en este sentido una auténtica "anarchie notionnelle".

Huelga decir que el presente trabajo se enmarca en el estricto punto de vista jurídico, sin reparar en cuestiones de índole política que desvirtuarían su objeto.

Dicho esto, conviene aclarar que cuando hablamos de "intervención económica" nos estamos refiriendo a todo aquel conjunto de técnicas y medidas que adopta la Administración para actuar en el plano o ámbito económico del país. Esas técnicas pueden orientarse tanto al más contundente intervencionismo (de recursos y/o actividades y/o empresas) como al más permisivo abstencionismo (liberalización, desregulación y privatización), sin olvidar otras medidas clásicas como la política fiscal, las subvenciones y estímulos, etc. 
Todas estas opciones tienen como sujeto activo al Poder Público, a la Administración, al Estado; y como sujeto pasivo, al individuo o a "los privados" como colectivo.

Esto es, se pueden establecer medidas para aumentar o bien limitar la autonomía económica del particular o de un conjunto de ellos, lo que incidirá a su vez en el incremento o gravamen de su patrimonio jurídico.

En puridad, los conceptos enunciados de "aperturismo" y "abstencionismo" son poco precisos, ya que resulta reiterativo denominar "técnica de intervención intervencionista", amén de que las medidas abstencionistas no dejan de ser medidas interventoras de la economía.

En este sentido, resultaría más adecuado el manejo de conceptos como medidas, políticas o actuación administrativa "de restricción o limitación" y "de apertura", que toman como referencia el punto de vista del tráfico o de los operadores privados.

De este modo, la intervención pública en la economía sería el conjunto de técnicas que pueden operar tanto para restringir como para abrir y crear mercados, marcando y delimitando de este modo la dirección económica de un país.

No obstante, debido a la generalización de la dicotomía "abstencionismointervencionismo" desde la óptica jurídico-pública, se manejarán indistintamente ambas nomenclaturas.

\section{TÉCNICAS DE RESTRICCIÓN O LIMITACIÓN DE LA INICIATIVA PRIVADA: LA RESERVA DE ACTIVIDADES Y LA NACIONALIZACIÓN}

$\mathrm{Si}$, como más adelante señalaremos, liberalización y privatización buscan una "devolución"2 por parte de la Administración de actividades o bienes a los particulares, precisamente la técnica de reserva que nos disponemos a analizar contempla la asunción o incorporación de una actividad o recurso que permanecía en el sector privado para ejercerla o explotarla directamente

2 Entrecomillamos adrede el término, porque "devolver" implicaría una apropiación (debida o indebida) de un recurso o actividad que originariamente pertenecía al sector privado. No obstante, podemos afirmar que no existiría como tal un núcleo de materias reservadas en exclusiva a la iniciativa privada.

A pesar de que en muchos países se reconoce su participación en diversos sectores, como la educación y la sanidad, ello no implica una exclusión de la iniciativa pública, que podría intervenir en cualquier sector de actividad. En cambio, sí ha existido tradicionalmente un núcleo indisponible de actividades y recursos reservados a la iniciativa pública, perfilados desde la Paz de Westfalia de 1648 e identificados dentro del "núcleo duro" de la soberanía. Estas materias suelen plasmarse en las Constituciones de los diferentes Estados, identificándose con actividades como las relaciones internacionales, la Administración de Justicia, la Defensa y las Fuerzas Armadas, o la acuñación de moneda y timbre. 
la Administración o, de manera indirecta, los privados, pero siempre bajo un régimen de titularidad pública.

Estamos pues ante los fenómenos de la reserva o "publicatio"3 y de la nacionalización, conceptos que a pesar de estar íntimamente ligados resultan ser diferentes.

La reserva de actividades o "publificación" se encuentra de manera general en la mayoría de textos constitucionales, como por ejemplo es el caso del artículo 128.2 de la Constitución Española de 1978, el cual dispone: "Se reconoce la iniciativa pública en la actividad económica. Mediante Ley se podrá reservar al sector público recursos o servicios esenciales, especialmente en caso de monopolio, y asimismo acordar la intervención de empresas cuando así lo exigiere el interés general".

En cada ordenamiento jurídico concreto, según la configuración de la técnica se suscitarán diversas cuestiones jurídicas, como las referentes al tipo de ley necesaria para realizar la reserva, las mayorías exigidas (más o menos reforzadas), las garantías asociadas al proceso de reserva, etc.; no obstante, las consecuencias operativas son prácticamente las mismas.

Con la reserva se produce la asunción de la titularidad de una actividad o de un recurso que se considera esencial para la ciudadanía y que, como tal, pasa a depender de lo público, de la Administración.

Junto a la titularidad, también se asume la gestión. No obstante, los diversos ordenamientos jurídicos contemplan a su vez técnicas que permiten disociar y ceder la gestión sin pérdida de la titularidad, como es el caso de la gestión indirecta y la clásica concesión administrativa en los sistemas de corte francés.

La publificación adoptará las siguientes formas en función del objeto:

- Servicios y actividades à Servicio público

- Recursos y bienes à Dominio público ${ }^{4}$

3 La denominación de publicatio o "acto de publicatio" fue enunciada por primera vez, en derecho español, en el célebre trabajo de ViLLAR PaLASí (1964).

4 En ambas formas podríamos llegar a incluir a los denominados "monopolios fiscales" o "géneros estancados", pues se refieren tanto a un concreto objeto o recurso público (caso del petróleo, el algodón, el lúpulo, etc.), como requieren la realización de una serie de actividades para su transformación industrial y comercialización.

Su única finalidad es la de conseguir una serie de rentas para el Estado, sin prestar ningún tipo de servicio activo o beneficio a la comunidad de manera regular y continua, salvo los ingresos derivados de su explotación (BAENA DE ALCÁZAR, 1966).

En la actualidad, este tipo de fórmulas se halla en claro retroceso en el seno de los países desarrollados, habida cuenta del mayor auge del derecho de la competencia y el libre mercado internacional, que no permite la existencia de monopolios y de situaciones de abuso de posición de dominio en sectores de actividad tan importantes.

Es por ello que cualquier eventual restricción de la competencia o el otorgamiento de derechos de exclusiva deberán encontrar cobertura en razones de interés general, que no deben ser genéricamente argüidas sino concretamente demostradas. 
Para la gestión de ambas categorías se puede erigir, a su vez, otro clásico instrumento de intervención administrativa que, por motivos de extensión, resulta imposible analizar ahora. Nos referimos a la empresa pública.

A través de la misma, los poderes públicos pueden realizar una labor prestacional directa, organizando medios de producción y generando bienes y servicios. Esta fórmula puede actuar tanto en sectores de actividad reservados como no reservados, siendo una muestra de la actividad mercantil o industrial de la Administración.

Sentado lo anterior y volviendo a nuestro análisis, debemos tratar una cuestión importante previamente apuntada: publicatio no es sinónimo de nacionalización (Ariño Ortiz, 2004), ya que esta última, además de implicar la primera, conlleva una necesaria transferencia de propiedad de los medios materiales y de producción del antiguo titular a la Administración, lo que deriva en una serie de consecuencias añadidas.

De este modo, por ejemplo, cuando declaramos un actividad como servicio público (recogida de basuras, v.gr.), la Administración asume la titularidad de la misma. Pero ello no significa per se que la Administración vaya a despojar los bienes de las empresas que hasta entonces prestaban el servicio, o que impida totalmente la participación privada (permitiendo la gestión indirecta, p. ej.). En este caso, pues, no se habrá producido ningún tipo de nacionalización, solo una reserva o publicatio de la actividad.

Cosa distinta es que muchas reservas que recaen sobre importantes sectores de actividad (como la industria energética, las telecomunicaciones, etc.) impliquen a menudo también la apropiación de toda la infraestructura necesaria para realizar la actividad. Esto es lo que entendemos por nacionalización.

Es por ello que el proceso de nacionalización implica unas consecuencias mucho más traumáticas que la neta publicatio, por cuanto supone no solo que la Administración va a tener en principio la titularidad de la actividad, sino que va a hacerse cargo de todo el operativo y a actuar de manera directa en el desempeño de la misma, desposeyendo de tales bienes a los particulares.

Es en este punto cuando surge un tema clave y de gran trascendencia, tanto dogmática como práctica: ¿cabe indemnización por la reserva de actividad y/o bienes?

La cuestión, ciertamente apasionante, no puede ser tratada en profundidad, pero sí cabe señalar las principales conclusiones, que dependerán del concreto supuesto ante el que nos encontremos:

- Nacionalización: como hemos comentado supra, en este caso tenemos una reserva de la actividad o recurso más una incautación patrimonial de bienes afectos o conexos. Supone, por tanto, la transferencia de bienes y/o factores de producción, organizados o no en empresas, que pasan a ser de titularidad estatal. 
En estos casos, efectivamente, estaríamos ante una ablación patrimonial que resultaría plenamente indemnizable.

- Simple publicatio: supone una reserva sin incautación patrimonial alguna. Este supuesto es especialmente problemático.

De este modo, si el recurso o servicio no era utilizado o prestado por los sujetos privados o este venía siendo prestado por la Administración, es lógico que no se derive ningún tipo de indemnización, ya que no hay un daño cierto y efectivo que resarcir al sector privado.

Ahora bien, si existían sujetos privados titulares de un recurso o que venían ejerciendo una actividad o servicio, a pesar de que no hay una desposesión o sustracción efectiva de sus bienes o recursos, en realidad hay un perjuicio evidente para los particulares ya que se les priva del uso y utilización de los mismos, unido a una posible interrupción de su actividad empresarial.

\section{TÉCNICAS APERTURISTAS}

\section{A. LiberalizaCióN}

Genéricamente consiste en la apertura total o parcial al sector privado de actividades, productos o recursos que anteriormente se encontraban reservados a la Administración, ostentando esta última, pues, derechos de exclusiva.

La liberalización opera una supresión del monopolio, consistente en la renuncia por parte del Sector Público al control total y absoluto de un sector de actividad en general ${ }^{5}$. Se produce, por tanto, una despublificación (de modo inverso a la publicatio analizada), que se realizará a través de un acto formal expreso $^{6}$ (en virtud de ley, i.e.).

Ahora bien, hay que realizar un adecuado plan de liberalización para que se produzca verdaderamente la despublificación general de una actividad o servicio.

Hay que atender al "espíritu de apertura" que se encuentra intrínseco en el concepto de liberalización y tener presente que su combinación, en algunos

5 "Fundamentalmente, liberalización implica supresión de los monopolios y de aquellas actividades declaradas servicios públicos o nacionalizadas y que en consecuencia sólo los poderes públicos estarían habilitados para desarrollar. Liberalización supondría, así, fundamentalmente 'devolver' a la 'sociedad civil' y a la libre iniciativa económica lo que en virtud de actos de reserva estatales realizados en el pasado estaba acotado para la actuación de los poderes públicos. Éste es el contenido central y medular de la liberalización" (DE LA QUADRA, 2000, p. 31).

6 Tal y como expone De LA SERNA (1995): "sólo es posible utilizar el término liberalización cuando se procede a eliminar la reserva formal que existía a favor de los poderes públicos de la titularidad de la actividad o sector de que se trate". 
casos no solo recomendable sino necesaria, con instrumentos como la privatización y la desregulación, no garantiza per se la efectividad de esa finalidad teleológica.

Por ejemplo, si se liberaliza una actividad y la empresa pública monopólica que gestionaba el servicio se privatiza sin dar entrada a competidores, la toma de esta (lo que significaría virtualmente la toma del sector) no supondría poner la actividad a disposición de la sociedad, sino solo de los privados que se apoderasen del control de dicha empresa.

Señalemos aquí ya un importante matiz entre liberalización y privatización en relación con el concepto de "despublificación": Mientras la primera no supone atribución de titularidad a un sujeto determinado, sino a la sociedad en general (uti universi), la segunda sí implica una transferencia de bienes y derechos de contenido patrimonial público (empresas públicas, activos públicos de distinta índole, etc.) a uno o varios sujetos privados determinados (uti singuli).

Es por ello que, tal y como señalan Kay y Thompson, "La privatización tenderá a mejorar los resultados de una compañía sólo si se ve apoyada por la liberalización; y si ambas cuestiones entran en conflicto, decididamente es preferible la última" (1986).

De lo expuesto hasta ahora, por tanto, la principal idea que debemos extractar del concepto de liberalización es que, además de dar entrada a los operadores privados o de mercado a un determinado sector económico, se produce una ruptura del monopolio/reserva del poder público; a lo que deberíamos añadir para propiciar la existencia de un efectivo mercado competitivo: $\sin$ pasar a monopolio u oligopolio privado ${ }^{7}$.

Por tanto, vemos ya aquí cómo el derecho de la competencia se postula así también como objetivo auxiliar $\mathrm{y}$, al mismo tiempo, principal de toda liberalización.

A raíz de la eliminación de barreras de entrada públicas se produce la entrada de operadores económicos, originándose un mercado que deberá ser tutelado por un ente u organismo regulador y/o supervisor, inserto en la propia organización administrativa tradicional o recurriendo a fórmulas accesorias e institucionales al estilo de las "Agencies" y "Offices" anglosajonas, con un mayor o menor grado de independencia funcional.

En este último sentido, efectivamente la liberalización ha supuesto una reconsideración o replanteamiento del papel del Poder Público, hasta ese momento titular y gestor unitario de la actividad ${ }^{8}$, pasando a ejercitar ahora

7 "El usuario pasa a ser cliente, el servicio público un mercado, las tarifas precios" (GONZÁLEZVARAS IBÁÑEZ, 2012).

8 Uno de los motivos clásicos de intervencionismo público es la prestación de servicios deficitarios: "La circunstancia de que una actividad deje de ser deficitaria ha sido determinante para la finalización de monopolios estatales o sectores extraordinariamente intervenidos por los poderes públicos. Si una actividad puede prestarse en un mercado libre y compe- 
funciones de regulador del mercado o sector de actividad liberalizado, separándose actividades y creándose entes de supervisión, gestión y control de las redes necesarias para realizar tal actividad.

Podemos ciertamente concluir que la liberalización se garantiza a través de un eficaz marco regulatorio y órganos independientes que velen por la aplicación efectiva del derecho de la competencia.

Cristalinos ejemplos de esa tendencia a la liberalización son los numerosos procesos emprendidos en la Unión Europea, iniciados en el sector de las telecomunicaciones e implementados durante la década de los años 90 y 2000.

Tal fue el caso español, donde la primera gran ola liberalizadora se produjo en 1996, a consecuencia del Real Decreto-Ley 5/1996 (que afectó al suelo y a los colegios profesionales) y de los reales decretos 6/1996, 7/1996 y 8/1996, 10 y 11/1996, que afectaron a las telecomunicaciones, el régimen fiscal, la defensa de la competencia, la distribución de carburantes, los servicios sanitarios, los servicios funerarios y la ordenación farmacéutica.

Para concluir, muchas veces se asume (y se confunde) el hecho de que la liberalización trae consigo indefectiblemente la aplicación en todo su esplendor del derecho de la competencia, como si anteriormente a la liberalización no le fuera aplicable tal derecho, ya que el mismo solo puede tener sentido en condiciones de libre mercado 9 .

En esta afirmación hay gran parte de verdad, pero no completamente, ya que puede darse el derecho de la competencia aun en situaciones no propicias para la misma, o que a simple vista pudieran parecen contrarias. Tal es el caso, por ejemplo, de las situaciones tendentes al monopolio.

El derecho de la competencia no prohíbe las situaciones de dominio en el mercado; lo que prohíbe este derecho es el abuso de una posición de dominio, que limite los derechos de los consumidores, proveedores, imposición de barreras de entrada, etc. (Whish, 2012).

titivo, en que los derechos de los ciudadanos-consumidores estuvieran garantizados, no parece que existieran razones para retener la actividad en el sector público, sobre todo si la razón de su pertenencia al mismo se debe al carácter deficitario de la actividad" (LINDE PANIAGUa, 2004).

9 De hecho, el fomento de la competencia asociado al sector privado fue uno de los motivos

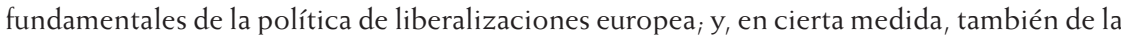
política de privatizaciones. En este sentido, "se consideró axiomático que la competencia en el mercado es un comportamiento característico de la empresa privada. La empresa pública ni por tradición, ni por disposición (se gestiona siguiendo pautas burocráticas y

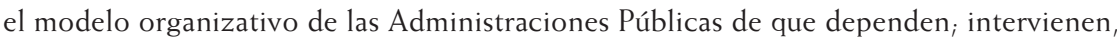
además, en la gestión políticos y funcionarios), se desenvuelve cómodamente en el mercado libre. Por otra parte, la dimensión territorial de los Estados condiciona la expansión de sus empresas, que se ajustan al espacio de la propia soberanía estatal. Este condicionamiento no existe en el caso de las empresas privadas" (MuÑOZ MACHADO, 2011). 
Salvando este apunte, es totalmente cierto que la aplicación del derecho de la competencia está conformado para que, valga la redundancia, haya competencia. Sin la existencia de multitud de operadores económicos o de mercado que puedan competir libremente bajo la supervisión de un órgano que marca las "reglas del juego", se mitiga bastante su virtualidad práctica.

\section{B. PRIVATIZACIÓN}

Cuando hablamos de "privatización", por lo general, aludimos a una forma de intervención pública en la economía que permite la adquisición, por parte del sector privado, de distintos tipos de derechos sobre bienes y/o actividades que anteriormente pertenecían al Sector Público, comprendiendo diversos fenómenos en su seno.

Con la privatización, por tanto, lo que se persigue es una mayor influencia de los operadores privados, en diversos niveles y gradación.

Es realmente complejo dar un concepto de privatización. Veamos la definición de privatización formulada por diversos autores:

- "Privatización es hacer privado o devolver al sector privado (bienes o actividades públicas). En términos generales, consiste en el abandono por el Estado de la producción de bienes y servicios" (Veljanovski, 1988).

- "Asunción por los particulares de bienes o actividades económicas anteriormente de titularidad o gestión pública" (Martín Mateo, 1988).

- "Retirada del Estado de las actividades económicas anteriormente de titularidad o gestión pública" (Ariño Ortiz, 1992).

- "Devolución de tareas o servicios realizados hasta entonces por entidades públicas a empresarios o titulares privados" (Hamer, 1985).

Si observamos las anteriores definiciones, comprobamos que es bastante común incluir en el concepto de privatización aspectos que estarían propiamente ínsitos en la noción de liberalización ("devolución" de actividades de anterior titularidad pública, i.e. $\left.{ }^{10}\right)$.

Es por ello que es importante recordar que, aunque aconsejable, se puede propiamente practicar una privatización sin liberalizar, manteniendo pues la titularidad pública sobre el recurso y/o actividad.

Ahí precisamente está la clave de la distinción entre liberalización y privatización, ya que mientras la primera supone una auténtica apertura del recurso o actividad en general, no requiriéndose por parte de los privados mayores requisitos que los que puedan derivar del nivel de regulación y control del objeto

10 De hecho, incluso el Diccionario de la Real Academia de la Lengua Española, respecto a "privatizar", consigna que consiste en: "Transferir una empresa o actividad pública al sector privado" (www.rae.es). 
en cuestión, la segunda consiste en una simple entrada, aumento de participación o influencia, sobre un recurso o actividad en concreto respecto del cual el Sector Público ejerce una singular relación de sujeción (derechos de propiedad, básicamente).

En otro orden de cosas, uno de los aspectos fundamentales a destacar es que el término "privatización" es polisémico. La palabra alberga o abriga distintas formas de dar entrada a la iniciativa privada en actividades, servicios y bienes tradicionalmente reservados a la iniciativa pública, lo que ha supuesto que gráficamente se le denomine "término paraguas".

Por otro lado, si resulta complicado delimitar un concepto de privatización, lógicamente existe idéntica o mayor dificultad a la hora de determinar una clasificación que resulte en cierto modo pacífica y que contemple los fenómenos privatizadores más importantes, y que no se convierta en una extensísima enumeración de los efectos que puedan derivarse de tales procesos ${ }^{11}$.

Diversos autores, como González-Varas (2012), realizan una sistematización que consideramos que refleja adecuadamente las distintas facetas en que se puede desdoblar el concepto de privatización. De este modo, podemos encontrarnos, principalmente, con tres tipos acepciones de privatización:

- Privatización formal: la Administración utiliza formas, métodos, organización y técnicas de derecho privado en la realización de determinadas actividades con el fin de obtener mayor agilidad y evitar todo el conjunto de procedimientos, trámites y controles que derivan del ordenamiento jurídico-público, y a los que se achaca lentitud y anquilosamiento a la hora de alcanzar determinados objetivos.

Englobado dentro de lo que podríamos denominar "New Public Management", este tipo de privatización ha dado lugar al fenómeno de la "huida del derecho administrativo o hacia el derecho privado", productor de auténticos ríos de tinta doctrinales.

Sin poder detenernos en este aspecto, básicamente se referiría a los indeseables y disruptivos efectos que se han derivado del excesivo recurso de la Administración a formas jurídico-privadas y mercantiles, que le han hecho alejarse del derecho que le es propio y aplicable, caracterizado por mayores dosis de control y fiscalización, esto es, el derecho administrativo.

- Privatización material o sustancial: consiste en la enajenación, de manera total o parcial, de derechos, bienes y recursos pertenecientes a la Administración, a través principalmente de procesos de venta de participaciones públicas y su consiguiente adquisición por los privados (Bös,

11 En este sentido, PIRIE (1985) identifica veintidós tipos de privatización distintos: venta total, parcial, donación, liquidación de empresas, por su parte, observa diez técnicas diferentes de privatización (RAPP, 1986). 
1987; Boardman, 1989). Es por ello que también es denominada "privatización de capital"12.

- Privatización indirecta ofuncional ${ }^{13}$ : también denominada "privatización organizativa", ciertamente, es el modo privatizador más dudoso desde la óptica y tradición jurídico-administrativa de corte francés y continental europea, ya que consistiría en una simple gestión indirecta de una actividad o recurso que sigue permaneciendo en mano y titularidad pública. Aunque, defacto, entran "privados" a gestionar y ejercer actividades antes prestadas directamente por la Administración, formalmente el control y la titularidad siguen siendo públicos.

Esta nomenclatura responde más a las necesidades conceptuales de los países de corte anglosajón receptores del Common Law, que carecen de categorías jurídicas clásicas como la concesión y el concierto.

\section{DesRegulación}

Esta última técnica requiere de una especial matización, pues propiamente no estaríamos tanto ante una técnica aperturista como ante una técnica de "better regulation" administrativa.

Aunque tras el transcurso de las años ya no suele confundirse desregulación con "quitar normas"14 o con la simple eliminación del ordenamiento jurídico de aquellas normas "que más me molestan como operador económico"15, resulta no obstante necesario delimitar bien el concepto.

De la Serna lo comprende del siguiente modo: "Se puede definir la desregulación/desreglamentación básicamente como la eliminación, modificación o simplificación, por parte de los poderes públicos, de aquellas normativas o trámites administrativos que de alguna manera limiten, condicionen o restrinjan la iniciativa y el desarrollo de las actividades de contenido económico tanto públicas como privadas" (1995).

12 Utilizado en Francia el término "privatisation capitalistique", no debe entenderse en un sentido ideológico, sino en el sentido de una operación sobre el capital de una empresa determinada.

13 Vendría referido a la asunción por parte de los operadores privados de tareas de contenido económico que antes prestaba la Administración, posicionándose esta como simple supervisor de la actividad o sector en general. También cabría dentro de esta definición el estado resultante tras una liberalización, siendo en cierta medida impropia la utilización del término privatización.

14 JACQUES CHEVALIER (1987) señala que, aunque el término inglés deregulation puede ser traducido en francés como déréglementation, desregulación (retroceso de la intervención estatal) y desreglamentación (extracción de normas) no son sinónimos. Otro estudio destacable del mismo año lo encontramos en SEPE (1987).

15 "Rigid regulations inbibit private initiative" ("Las regulaciones rígidas inhiben o disuaden la iniciativa privada") (World Bank, 1997). 
No obstante, a esta definición le faltaría añadir el elemento de la novación normativa. Es por ello que sería más correcto en todo caso hablar de "neo-regulación" o, mejor aún, de "reestructuración o actualización normativa". Esta expresión refleja con mayor exactitud el proceso de simplificación normativa que se conoce en Alemania como "Minimalregelung", combinado con el erguimiento de otras normas que sustituyen a las anteriores en aras de dar mayor claridad y soltura a una actividad económica determinada. La idea de agilizar los procedimientos y a la vez lograr una mejor atención de los usuarios de la actividad es una idea siempre subyacente en la desregulación.

Rivero Ortega (2007) ha señalado que este fenómeno recuerda al ideal de la codificación (coherencia normativa, reducción de elementos imprecisos o innecesarios, etc.), precisamente en la "era de la descodificación".

No obstante, ese es el principal error al plantear la desregulación: considerar que es sinónimo de pura reducción de normas. Es más, con el objetivo de dinamizar la libre competencia, lo que se ha conseguido es el efecto contrario, una mayor densidad normativa (De la Quadra, 2000; Usher, 1992; RoseAckerman, 1993; Cohen-Tanugi, 1985).

Ejemplo típico es la desregulación de barreras de entrada, rutas y tarifas en el transporte aéreo en Estados Unidos, que se tradujo en una mayor regulación y exigencias sobre formación de pilotos y seguridad, disminuyendo el número de accidentes y permitiendo un incremento notable del uso del avión por los particulares (Pierce y Gellhorn, 1999).

Pierce y Gellhorn (ibíd.) señalan que el movimiento desregulador suele desarrollarse en cuatro fases: cuestionamiento de las estructuras normativas y reguladoras de una actividad o sector por parte de la doctrina científica (1), aparición de estudios empíricos que muestran que una excesiva rigidez y falta de flexibilización normativa benefician situaciones anticompetitivas (i.e., empresas tradicionalmente dominantes), perjudicando al consumidor y la formación competitiva de diversos aspectos como los precios, las inversiones, etc. (2); ecos de estas iniciativas en sede ejecutiva, pudiendo tener influjos en la adopción de determinados cambios de regulación por parte de los órganos o entes responsables ( 3$)_{i}$ renovación del marco normativo y formalización en sede parlamentaria del proceso de desregulación iniciado por vía ejecutiva (4).

A su vez, por otra parte, es bastante común asimilar el significado de la desregulación con el concepto de la liberalización, sobre todo si atendemos a la concepción anglosajona de deregulation y al uso que del término realiza la ciencia económica.

Ahora bien, conforme a una tradición romano-germánica no habría que confundir ambos términos. Expliquemos el porqué.

Los países de la Common Law, sobre todo Estados Unidos, suelen utilizar indistintamente los términos deregulation y liberalization (o liberalisation) para referirse a dos realidades, en nuestra opinión, distintas: apertura de un sector previamente público, sinónimo de despublicatio; y, en el caso de que el sector 
ya se encontrara accesible y no hubiera reserva en exclusiva (lo que es la práctica totalidad de actividades en este contexto anglosajón), la supresión y/o disminución de las tareas de regulación y control que fomenten el más o menos limitado juego de los operadores económicos privados (desregulación en sentido propio).

La razón de ello es que, en la tradición norteamericana, la regulation (Melnick, 2002) sería el régimen de partida a través del cual el sector público interviene (especialmente a través de las Agencies y Offices) en una economía que tiene una base generalmente liberalizada.

Por tanto, normalmente, cuando se utiliza la locución liberalization se está empleando en el sentido de la desregulación apuntada, como la referencia a una orientación destinada a una mayor presencia de los operadores privados en el sector de que se trate $y$, consecuentemente, a la disminución de coerción pública a través de distintas medidas, tales como la eliminación de fases de supervisión y control, la simplificación procedimental, etc.; todo ello salvaguardando una adecuada competencia y calidad en la prestación de los servicios.

Por el contrario, en los países de la Europa continental el punto de partida es la tradición francesa del servicio público, del cual detenta la Administración la titularidad exclusiva, siendo pues la regulación la nueva orientación del papel del Estado que crea mercados y asegura el marco adecuado donde pueden operar las diversas técnicas aperturistas.

Por último, debemos señalar otro matiz importante: la desregulación se puede operar tanto en sectores liberalizados como no liberalizados. Per se, la desregulación no requiere un previo proceso liberalizador ya que lo que se logra con esta técnica es una mayor racionalización del sistema normativo aplicable. Es cierto que pueden darse mayores dosis de aperturismo con este tipo de medidas, pero ese no es propiamente el sentido teleológico de este instrumento.

\section{CONCLUSIÓN}

Se ha producido una evolución que es, a grandes rasgos, predicable de casi todos los países de corte occidental, que consiste en una reducción desde la década de 1970 del protagonismo público en el desarrollo de la actividad económica (Cameron y Neal, 2010).

De esta manera, hoy podemos confirmar la expansión del fenómeno liberalizador (despublificación), privatizador y desregulador -contrario a la anteriormente extendida política de creciente publificación y nacionalización-, y que ha supuesto (y está suponiendo) la puesta en manos privadas de sectores, actividades y empresas hasta entonces en mano pública.

Ahora bien, parece claro también que atrás queda el viejo adagio del laissez faire et laissez passer, le monde va de lui même ("dejad hacer, dejad pasar, el mundo 
marcha solo"), propio de un capitalismo primitivo o, tal y como denominó Stiglitz (2002), del "fundamentalismo de mercado" (market fundamentalism).

La reciente crisis económica iniciada en 2007-2008 da buena muestra de cómo la fórmula de la autorregulación del mercado es ineficaz; el expansionismo económico perpetuo y ad infinitum en un mundo con recursos y espacio necesariamente finitos es una aporía difícilmente soslayable (Meadows, 1972).

Es necesaria la cobertura y supervisión del Estado como garante de una eficiente marcha del mismo; eso sí, también dicho sea de paso, sin apoyarse en un keynesianismo estricto, antagonista del citado laissez faire. Es más, si atendemos a la evolución de la intervención económica, comprobamos que la iniciativa pública siempre ha estado presente; es decir, nunca ha habido (ni en gran medida es posible) una completa "entrega" o manejo privado de todos los sectores de actividad.

A modo de reflexión final, podemos concluir que ni la autorregulación del mercado ni el intervencionismo extremo son la solución adecuada.

A lo largo de la historia tanto sector público como el sector privado han tenido épocas de expansión y contracción, concepto que es gráficamente denominado en Francia "técnica de la respiration".

Desde nuestro punto de vista, la idoneidad o desaconsejo de opciones aperturistas (liberalización, privatización, desregulación) o limitadoras de la iniciativa privada (nacionalización, empresa pública) dependerá de si se ha producido tal protagonismo de uno u otro signo que ha derivado en unas consecuencias negativas para la ciudadanía en términos de prestación del servicio, desequilibrios del sector, etc.; ya que este y no otro debería ser el único objetivo que motivase cualquier tipo de actuación pública, incluida la intervención económica: la satisfacción de los intereses generales, subjetivamente identificados en los ciudadanos-administrados.

El cumplimiento de este fin último no nos permite intelectualmente la adopción de posiciones apriorísticas, máxime cuando también comprobamos que el mayor o menor protagonismo de "lo público" o "lo privado" responde a procesos cíclicos, pendulares.

Al igual que mecanismos como la expropiación forzosa o la sanción pueden utilizarse de manera correcta o incorrecta, nacionalizaciones y privatizaciones pueden utilizarse de una manera beneficiosa o perversa.

Dependerá de los gestores públicos y, más todavía en la sociedad actual, de los propios ciudadanos ${ }^{16}$, controlar y fiscalizar la adecuación de todos

16 El ciudadano, como parte de la sociedad civil organizada o "Tercer Sector", se está posicionando cada vez más ya no como mero sujeto pasivo receptor de actuaciones administrativas, sino como auténtico sujeto activo que demanda una acción pública eficaz y de calidad. En este último sentido, cada vez más se están positivando vías a través de las cuales los ciudadanos puedan exigir de los poderes públicos responsabilidades, como es el caso del denominado "Derecho de Buena Administración", que a nivel europeo ha sido 
estos procesos de cara a preservar su carácter beneficioso, y desechando sus consecuencias negativas.

\section{BIBLIOGRAFÍA}

Ariño Ortiz, G. (2004). Principios de Derecbo Público Económico. Granada: Comares.

Baena De AlCÁZAR, M. (1966). Régimen jurídico de la intervención en la economía. Madrid: Tecnos.

Botrdman, A. y A. Vining (1989). Ownership and Performance in Competitive Environments: A Comparision of the Performance of Private, Mixed, and StateOwned Enterprises. Journal of Law and Economics. Vol. 32 (1).

BöS, D. (1987). Privatization of public enterprises. European Economic Review, vol. 31.

Cameron, R. y L. Neal (2010). Historia Económica Mundial. Desde el paleolítico hasta el presente. Madrid: Alianza.

Chevalier, J. (1987). Les enjeux de la déréglementation. Revue du Droit Public, n. ${ }^{\circ} 2$.

Cohen-Tanugi, L. (1985). Le Droit sans l'État (Sur la democratie en France et en Amérique). Paris: Presses Universitaires de France.

De La Quadra, S. y T. Fernández Del Castillo (2000). Constitución y modelo económico liberalizador. Cuadernos de Derecho Público, n. ${ }^{\circ} 9$.

De La Serna BilbaO, M. N. (1995). La privatización en España. Fundamentos constitucionales y comunitarios. Pamplona: Aranzadi.

GonZÁlez-Varas IbáÑeZ, S. (2012). Tratado de Derecho Administrativo, t. VI, Derecho Administrativo Económico. Navarra: Thomson-Civitas.

Hamer, E. (1985). Praxis de la privatización de servicios. Revista del IEE, n. ${ }^{\circ} 1$.

Kay, J. A. y D. J. Thompson (1986). Privatisation: A Policy in Search of a Rationale. Economic Journal, n. 96.

incluso reconocido como derecho originario o primario europeo, al mismo nivel que los tratados constitutivos, y reconocido en la Carta de los Derechos Fundamentales de la Unión Europea del 7 de diciembre de 2000.

Para un análisis amplio de esta cuestión, v. mi trabajo al respecto, SAURA Fructuoso (2012). 
Linde Paniagua, E. (2004). La retirada del Estado de la sociedad: Privatizaciones y liberalización de servicios públicos. Revista de Derecho de la Unión Europea, n. ${ }^{\circ} 7$.

MARTín MATEO, R. (1988). Liberalización de la economía (más Estado, menos Administración). Madrid: Trivium

Meadows, De y Meadows, Do y J. Randers (1972). The Limits to Growth: A report for the Club of Rome's Project on the Predicament of Mankind. New York: Universe Books.

Melnick, R. S. Regulation. En K. Hall y D. S. Clark (2002). The Oxford Companion to American Law. Oxford/New York: Oxford University Press.

Muñoz Machado, S. (2011). Tratado de Derecho Administrativo y Derecho Público General, vol. I, La Formación de las Instituciones Públicas y su sometimiento al Derecho. Madrid: Iustel.

Pierce, R. J. y E. Gellhorn (1999) Regulated Industries in a Nutshell, 4. a ed. Minessota: West.

PIRIE, M. (1985). Teoría y práctica de la privatización. Revista del IEE, n. ${ }^{\circ} 1$.

Rapp, L. (1986). Techniques de privatisation des entreprises publiques. Paris: Librairies Techniques.

Rivero Ortega, R. (2007). Derecho Administrativo Económico. Madrid: Marcial Pons.

Rose-Ackerman, S. (1993). Rethinking the Progressive Agenda: The Reform of the American Regulatory State. New York: Free Press.

Saura Fructuoso, C. (2012). El Derecho de Buena Administración y el "Due Process" Administrativo Europeo. Procedimiento Administrativo Europeo. Madrid: Civitas.

SEPE, O. (1987). Un convengo internazionale sulle "deregolamentazioni". Rivista Trimestrale di Diritto Pubblico, n. ${ }^{\circ} 2$.

Stiglitz, J. E. (2002). Globalization and its Discontents. New York: W.W. Norton.

Usher, D. (1992). The Welfare Economics of Markets, Voting and Predation. Ann Arbor: University of Michigan Press.

Veljanovski, C. (1998). Selling the State, Privatisation in Britain. London: Wedenfield.

VILlar Rojas, F. J. (1992). La privatización de servicios públicos. La experiencia española a la luz del modelo británico. Madrid: Tecnos.

Villar Palasí, J. L. (1964). La intervención administrativa en la industria. Madrid: Instituto de Estudios Políticos. 
Whish, R. y D. BAILeY (2012). Competition Law. Oxford: Oxford University Press.

World Bank. (1997). World Development Report: The State in a changing world. Washington D.C.: World Bank. 